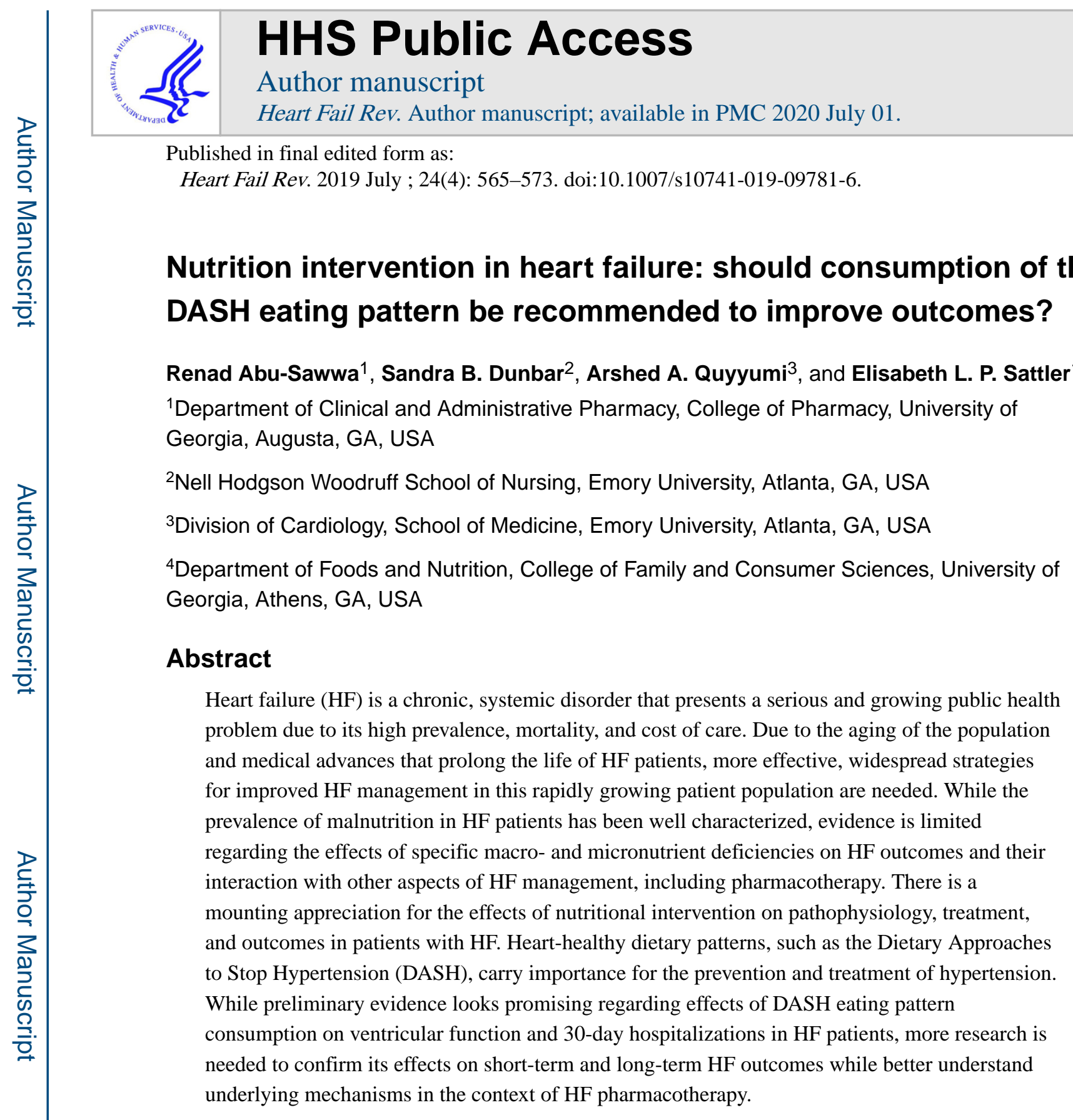

\title{
Keywords
}

Heart failure; Nutrition; Intervention; DASH; Malnutrition

Correspondence to: Elisabeth L. P. Sattler.

Elisabeth L. P. Sattler, lilian@uga.edu.

Compliance with ethical standards

Financial disclosures Drs. Abu-Sawwa, Sattler, Dunbar, and Quyyumi have no conflicts of interest or financial ties to disclose.

Ethical standards The manuscript does not contain clinical studies or patient data.

Publisher's note Springer Nature remains neutral with regard to jurisdictional claims in published maps and institutional affiliations. 


\section{The burden of heart failure}

Heart failure (HF) is a systemic disorder that presents a serious and growing public health problem due to its high prevalence, mortality, and cost of care. Approximately 6.5 million Americans aged 20+ years lived with a diagnosis of HF based on the National Health and Nutrition Examination Survey 2012-2014, and projections show that this number will increase to over 8 million by the year 2030. Total medical cost attributable to HF was $\$ 30.7$ billion in 2012, about $80 \%$ of which were related to hospitalizations [1]. Older Americans are more often hospitalized for HF than for any other condition [2]. Most (83\%) of HF patients are hospitalized at least once, and $45 \%$ are hospitalized four times or more post diagnosis [1]. With $29.6 \%$ of Medicare beneficiaries not surviving the first year after a HF hospitalization, mortality in this population remains high [3]. Given that rehospitalization, death, and high cost of care are most likely in those previously hospitalized, emphasis has been placed on strategies to reduce the rate of HF hospital readmissions through policy imposing financial penalties for hospitals with excessive 30-day readmission rates, efforts to increase implementation of evidence-based prevention and treatment approaches in ambulatory and hospital settings, and new preventative measures and therapies, including the use of implantable hemodynamic measurement devices [4]. Due to the aging of the population and medical advances that prolong the life of HF patients, more effective, widespread strategies for improved HF management in this rapidly growing patient population are needed.

\section{Dietary sodium restriction in HF management}

Arguably the most heavily debated HF treatment strategy has been dietary sodium restriction $[5,6]$. Assumed to be a cornerstone of optimized HF self-management, various levels of sodium restriction have been endorsed by clinical guidelines despite low levels of evidence (e.g., expert opinion, level of evidence C). Intake recommendations vary widely from 3000 to $4000 \mathrm{mg} / \mathrm{day}$ ("moderate"), as recommended by the American College of Cardiology/ American Heart Association, to less than $2000 \mathrm{mg} /$ day in moderate to severe HF, as recommended by the HF Society of America. In contrast, the 2016 European Society of Cardiology HF Guidelines omits sodium intake recommendations entirely due to the weak evidence base [7]. Moreover, the American Heart Association recommends a more stringent sodium intake restriction of $1500 \mathrm{mg} /$ day for the general population than for HF patients, which appears as a paradox [5]. Heart failure pathophysiology is characterized by systolic and diastolic abnormalities of the myocardium that result in reduced cardiac output (CO) and reduced renal perfusion. These trigger compensatory mechanisms, including left ventricular dilatation and activation of the sympathetic and renin-angiotensin-aldosterone systems (RAAS) which lead to a vicious cycle of systemic vasoconstriction, increased blood pressure and heart rate, and sodium and water retention despite existing volume overload. Physiological and mechanistic studies have shown that dietary sodium restriction leads to further neurohormonal activation, is not associated with an improvement in glomerular filtration rate or natriuresis, and may result in increased plasma renin activity (PRA), worsened cardiac remodeling, and increased HF symptoms even in the presence of pharmacotherapeutic blockage of the RAAS. High PRA is an independent predictor of mortality in high-risk HF patients [8, 9]. Furthermore, evidence from few randomized 
controlled trials suggests either no benefit of sodium restriction on clinical improvement, diuretic therapy, and hospital readmission rates $[10,11]$ or lower mortality and hospital readmission rates for patients receiving a moderate $(2800 \mathrm{mg} /$ day $)$ vs. low-sodium $(1800$ $\mathrm{mg} / \mathrm{day}$ ) diet $[12,13]$. A meta-analyses of nine randomized controlled studies demonstrated a lack of high-quality evidence (e.g., small sample sizes) and inconclusive results regarding the improvement of clinical outcomes in both inpatient and outpatient HF patients with dietary sodium restriction [14]. The need for more robust evidence has been emphasized in a joint executive summary from the US National Heart, Lung, and Blood Institute and the National Institutes of Health Office of Dietary Supplements [14]. Support to restrict dietary sodium stems mostly from observational studies that have shown greater symptom burden, increased HF hospitalizations, increased need for heart transplantation, and increased mortality in patients with greater sodium intake over an extended period of time, using the gold standard 24-h urine sodium excretion method to estimate dietary sodium intake [1519]. Understanding the true independent effect of sodium consumption on HF outcomes appears to be a difficult undertaking. Such efforts would include addressing limitations of previous studies by using adequately designed and powered RCT to assess the effect of sodium consumption in the context of pharmacotherapy, fluid and nutrient intake on important HF outcomes, using validated measures, and long-term follow-up.

\section{Malnutrition in HF patients}

The etiology of malnutrition in HF patients is likely multifactorial and intertwined (Fig. 1). Anorexia, characterized as both inadequate food intake and suppressed appetite, can be attributed to the underlying pathophysiology of their disease, defined by a chronic inflammatory state and fluid overload, which leads to nausea, loss of appetite and early satiety from gastrointestinal edema, and hepatic congestion [20, 21]. The development of appetite suppression, early satiety, and insulin resistance is further exacerbated by neurohormonal etiologies of anorexia [1]. For example, leptin-induced anorexia has been characterized in patients with cardiac cachexia, as evident with significant decreases in leptin levels [20]. Reduced energy intake and negative energy balance have been associated with lower intake of all macronutrients, including total and saturated fat, protein, and carbohydrate intake [10-12]. Unfortunately, sodium restrictive diets, often recommended to HF patients, could potentiate decreased food intake due to decreased palpability of foods which is problematic in the context of chemosensory impairments commonly present in older adults [22]. As a consequence, sodium-restricted diets may contribute to anorexia and poor nutritional status in this population. With increasing HF progression, malnutrition is further exacerbated by increased energy requirements from higher resting metabolic rates in patients with severe HF [23]. Patients with HF are in a hypercatabolic state with increased levels of catecholamines, including epinephrine, norepinephrine, and cortisol, and decreased anabolic hormones, such as insulin-like growth factor [24]. Increased catecholamine levels likely contribute to malnutrition in HF patients through the development of intestinal ischemia with decreased splanchnic circulation leading to increased permeability and increased inflammatory cytokine release and can attribute to malabsorption of lipids on the one, and excessive protein loss on the other hand [4]. Therefore, HF disease pathophysiology predisposes patients to a disadvantage in nutritional status, as patients with 
$\mathrm{HF}$ are experiencing malnutrition from an energy imbalance arising from increased energy requirements and decreased energy intake.

Malnutrition in patients with HF has been associated with cardiac cachexia, a serious complication of HF, characterized by loss of lean muscle, fat, and bone tissue, and a risk factor for HF prognosis and mortality that is independent of HF severity, left ventricular ejection fraction, exercise capacity, and patient age [25]. Cardiac cachexia is defined as unintended, edema treatment-independent weight loss equal to at least $6 \%$ of body weight within 6-12 months and is a result of pathophysiological manifestation and progression of HF [25]. Half of patients with HF have some degree of malnutrition, with $15 \%$ being in a state of cardiac cachexia $[24,26]$. The progression of cardiac cachexia is strongly associated with increasing levels of functional decline, as demonstrated by NYHA classification [27]. In addition, mortality rates are increased in patients with cardiac cachexia, with rates up to $50 \%$ as compared with $17 \%$ in non-cachectic patients [24]. Abnormal metabolism and a chronic inflammatory state, characterized by excessive release of tumor necrosis factor (TNF)-alpha, previously termed cachexin, represent the underlying etiologies of cardiac cachexia. The effect of TNF-alpha on muscle wasting can be explained by its direct effect on the endothelium and by mitigating cell apoptosis and activating protein degeneration through which lean tissue mass is weakened in both structure and function [26, 28]. This chronic systemic inflammatory state is further worsened by the release of oxidative species and intestinal microorganism and/or endotoxin translocation, due to the intestinal edema that results from fluid overload due to $\operatorname{HF}[25,26,28,29]$. Avicious cycle ensues, as cardiac dysfunction manifests (e.g., reduced cardiac output) which in turn leads to cascading downstream effects including intestinal hypoperfusion, peripheral edema, and mucosal permeability. These factors affect normal processes of nutritional intake and absorption [24$26,29]$. In addition, patients with cardiac cachexia show heightened circulating levels of the metabolic hormone adiponectin, which is associated with lean muscle wasting and represents an independent risk factor for mortality [30, 31].

Due to the pathophysiological link between malnutrition and HF, several studies have investigated the prognostic impact of nutrition on HF outcomes, using nutritional assessment indices based on biochemical and clinical markers, including serum albumin, total cholesterol levels, and total lymphocyte count [4,5]. Scores that represented poorer nutritional status were associated with longer hospital stays, in-hospital mortality, progressive HF requiring readmission, and cardiovascular events [32-34]. While there are limitations to these indices due to an underlying pathophysiological state of inflammation in HF per se, they may detect both poor malnutrition and cardiac cachexia. For example, prealbumin, a clinical marker of nutritional status, could be indicative of protein malnutrition or altered due to disproportionate mobilization of muscle and degradation of protein [35].

Unlike non-cardiac patients, there is no significant association between dietary energy intake and body mass index (BMI) in persons with HF, as the nutritional status of HF patients is greatly influenced by variables outside of dietary energy consumption alone [10]. Therefore, use of BMI as a sole factor in nutritional assessment as a means of risk stratification is not recommended, particularly as it masks malnutrition in the presence of edema which 
complicates accurate weight measurements [36, 37]. Furthermore, malnutrition is present even in overweight and obese HF patients, as is illustrated in a study that found malnutrition in $22 \%$ of overweight HF patients in their sample [38]. While overweight and obesity have been identified as risk factors for HF development, patients with existing HF and higher than normal BMIs have shown to have improved outcomes and rates of survival, a phenomenon appropriately termed the obesity paradox [24]. Such paradox has been explained by (1) neutralization of TNF-alpha and lipopolysaccharides through excess adipose tissue and by (2) the fact that obesity among HF patients is associated with younger age, increased albumin levels, and increased lean muscle mass, strength, and exercise tolerance [39]. Generally, overweight and obese HF patients tend to have better nutritional and functional status than their normal and underweight counterparts.

\section{Micronutrient deficiencies in HF}

Micronutrient deficiencies commonly observed in HF patients may be attributed to malnutrition and underlying pathophysiologic mechanisms of HF. Most of the literature describes decreased micronutrient intake in patients with HF compared with the recommended reference nutrient intake; however, the ability of patients with HF to meet the daily recommended intake for both macro- and micronutrients is uncertain. In addition, while malnourished patients with HF experience an increased risk of cardiac cachexia and mortality, it is not clear from experimental evidence whether underlying micronutrient deficiencies are in the causal pathway [20]. Reduced energy intake in HF patients has been associated with lower intake of micronutrients, including magnesium, iron, phosphorous, potassium, selenium, zinc, sodium, B vitamins, and vitamin E [10-12]. Depleted micronutrient status, in turn, has been associated with an increase in mortality in patients with HF, most notably with serum potassium less than $4 \mathrm{mmol} / \mathrm{L}$ [8]. Moreover, a larger number of micronutrient deficiencies have been shown to be associated with significantly shorter event-free survival, therefore underlining the importance of micronutrient status and high-quality dietary intake [40].

Despite such important evidence, dietary management of HF in clinical practice has historically emphasized the reduction of a single micronutrient (i.e., sodium) and fluid management, which oversimplifies the complexity between multiple dietary inadequacies, including micronutrient deficiencies, and HF pathophysiology in these patients. Such information is particularly important within the context of an association between sodium restriction and decreased intake of other micronutrients, including calcium, phosphate, thiamine, and folate, in addition to reduced intake of energy and carbohydrates [2]. Various micronutrients are essential co-factors in energy metabolism and influencing cardiac and metabolic remodeling [41]. While deficiencies in HF patients have been described for micronutrients that are involved in carbohydrate and fatty acid metabolism, calcium homeostasis, renin production, and antioxidant properties, their effects on energy utilization, cardiac contractility, endothelial function, and reactive oxidative stress have not been fully described in patients with HF [20, 26].

In addition, little is known about micronutrient supplementation as a viable option to address micronutrient deficiencies in HF patients due to largely inconclusive results of intervention 
studies examining the effect of micronutrient supplementation on HF progression, morbidity, and mortality [20,26]. Finally, not one single component of nutritional status has been independently associated with changes in HF outcomes. Given that dietary intake and nutritional status are multifactorial concepts and research is generally limited in examining the independent effects of single foods and individual nutritional components on disease outcomes, assessment of dietary quality and patterns and nutritional status on HF outcomes is needed for improved understanding of the impact of micronutrient status on HF outcomes $[20,26,41-43]$.

\section{Impact of pharmacotherapy on nutritional status in HF}

A cornerstone of HF management is pharmacotherapy. While essential to comprehensive HF treatment, medications and nutrition interact through complex pharmacodynamic and pharmacokinetic relationships, such as by altering physiologic absorption, metabolism, and excretion of medications and nutrients within existing HF pathophysiology. In this context, recommended levels of macro- and micronutrients may not reflect true nutritional needs while accounting for underlying interactions [44]. Heart failure pathophysiology, poor quantity and quality of dietary intake, and concomitant pharmacotherapy have all been associated with malnutrition in HF patients [45]. By understanding the role of pharmacotherapy in the cause and exacerbation of malnutrition and its effects on underlying HF pathophysiology, appropriate modifications to both dietary and pharmacological management of these patients can be implemented. Loop diuretics, often used for symptomatic management of HF exacerbations, are notorious at increasing the urinary excretion of water-soluble micronutrients and thus contributing to micronutrient deficiencies, such as deficiencies of B vitamins and minerals, including potassium, calcium, magnesium, and selenium [24]. Angiotensin-converting enzyme inhibitors (ACEi), which are considered a cornerstone of chronic pharmacological management of HF due to their benefit on morbidity and mortality, have been shown to lead to zinc deficiency, taste distortions, and reduced appetite $[20,24,26]$. Digoxin, a medication often used in more severe HF progression, may lead to iatrogenic anorexia in patients with HF [26, 46]. Consequently, HF patients exhibit decreased food intake as a result of factors involved in the natural aging process and pathophysiological manifestations of their disease, which are potentiated by adverse medication side effects. Moreover, the combination of ACEi, digoxin, and diuretic medications has shown to increase subcutaneous fat and decrease muscle strength in patients with HF [24]. ACEi, angiotensin receptor blockers (ARBs), aldosterone antagonists, and thiazide diuretics alter the homeostasis of micronutrients, namely by increasing potassium levels by affecting the RAAS. Beta-blockers affect potassium levels by redistributing intracellular potassium into the serum as opposed to minimizing its excretion [24]. It is important to understand the individual effects of each medication class on nutritional status as deficiencies can easily be prevented, such as through supplementation of potassium to prevent hypokalemia. While studies have examined the supplementation of other micronutrients, including calcium, vitamin D, B vitamins (thiamine), vitamin C, vitamin $\mathrm{E}$, coenzyme $\mathrm{Q}$, selenium, zinc, copper, omega-fatty acids/fish oil, the data is largely inconsistent with no recommendations of routine supplementation unless deficiency is identified along with severe pathophysiology and/or drug-induced etiology [24]. Further 
investigation regarding the quantity and quality of dietary intake and within the context of pharmacological management of the underlying pathophysiology is vital to optimal medical management of patients with HF.

\section{Impact of the Dietary Approaches to Stop Hypertension (DASH) diet on HF outcomes}

The DASH diet emphasizes the intake of fruits and vegetables; lean protein such as poultry, fish, and nuts; fiber and whole grains; and low-fat dairy products in order to sustain adequate levels of micronutrients deemed to lower blood pressure, including potassium, calcium, and magnesium [47]. While the DASH diet has been proven to effectively reduce blood pressure, the benefit of the DASH diet in patients with HF has been inconsistently investigated [1, 19, 48-51]. However, due to the high percentage of HF patients with hypertension and the strong pathophysiological influence of long-standing hypertension in the development of HF $[1,52]$, beneficial effects of the DASH diet in HF patients are plausible. According to the World Health Organization, $75 \%$ of deaths from cardiovascular disease have been attributed to preventable risk factors, including dietary and lifestyle modifications. While the DASH diet and Mediterranean diets have shown to have a protective effect on the prevention of HF, there is limited literature suggesting a benefit on the slowing of disease progression, morbidity, and mortality in patients with existing HF [21, 53]. Diets consistent with DASH guidelines have been associated with lower incidence rates of HF in adults without baseline cardiac insufficiencies or disease, and to reduce blood pressure and LDL cholesterol levels $[21,47,54]$. The decrease in blood cholesterol levels can be partially attributed to a decrease in circulating fatty acids and glucose and an increase in dietary fiber content, which has been theorized to decrease the progression of cardiac hypertrophy and fibrosis, and overall decreased cardiac function as seen in HF [21, 55]. Based on the Framingham Heart Study, the decrease in systolic blood pressure is estimated to reduce the incidence of HF by about $12 \%$ [21]. Due to the known benefits of the DASH diet on cardiovascular disease, there have been preliminary studies assessing its effects on HF outcomes in patients with existing disease. In HF patients with preserved ejection fraction, DASH diet intake has shown to improve arterial elasticity, ventricular diastolic function, ventricular-arterial elastance coupling, and overall arterial stiffness [47, 54-57]. Clinically, a reduction in both blood pressure and 24-hour urinary sodium levels and an increase in 6-min walk distance and quality of life in patients with HF have been observed after consumption of a DASH diet [47, 54-58]. Mechanistically, the perceived benefit has been hypothesized to be associated with the prevention of the development and progression of endothelial dysfunction. Endothelial dysfunction, which is a surrogate for HF disease progression, is embodied by the interplay between impairments in the nitric oxide-mediated vasodilation, inflammatory cytokine cascade, and free radical production [47, 54]. Therefore, the positive effect on arterial elasticity and ventricular diastolic function from the DASH diet on patients with HF indicates a potential improvement in disease progression [47, 54]. Finally, a recent randomized controlled trial showed efficacy of home-delivered DASH meal consumption for 4 weeks post discharge from a HF hospitalization to reduce symptoms and functional status, and trended towards a reduction in 30-day hospital readmissions and days rehospitalized 
[58]. Thus, plausible explanations for the benefits of a DASH diet in HF are emerging to undergird further study.

\section{Where do we go from here?}

In conclusion, there is a mounting appreciation for the effects of nutritional status on the pathophysiology, treatment, and outcomes for patients with HF. There are well-established recommendations for the DASH diet in patients with hypertension [19, 48-51]. With growing research on the effect of the DASH diet and nutritional status on outcomes of cardiovascular diseases, and specifically HF, more detailed evidence on the effect of diet within the context of HF pathophysiology and medical HF management is needed (Table 1). At the least, consideration should be given to dietary intake and nutritional status beyond dietary sodium consumption to improve outcomes in HF patients.

\section{Acknowledgements}

Supported by the National Center for Advancing Translational Sciences of the National Institutes of Health under Award Numbers UL1TR002378 and KLTR002381. The content is solely the responsibility of the authors and does not necessarily represent the official views of the National Institutes of Health.

\section{References}

1. Benjamin EJ, Virani SS, Callaway CW, Chamberlain AM, Chang AR, Cheng S, Chiuve SE, Cushman M, Delling FN, Deo R, de Ferranti SD, Ferguson JF, Fornage M, Gillespie C, Isasi CR, Jimenez MC, Jordan LC, Judd SE, Lackland D, Lichtman JH, Lisabeth L, Liu S, Longenecker CT, Lutsey PL, Mackey JS, Matchar DB, Matsushita K, Mussolino ME, Nasir K, O'Flaherty M, Palaniappan LP, Pandey A, Pandey DK, Reeves MJ, Ritchey MD, Rodriguez CJ, Roth GA, Rosamond WD, UKA S, Satou GM, Shah SH, Spartano NL, Tirschwell DL, Tsao CW, Voeks JH, Willey JZ, Wilkins JT, Wu JH, Alger HM, Wong SS, Muntner P, American Heart Association Council on E, Prevention Statistics C, Stroke Statistics S (2018) Heart disease and stroke statistics-2018 update: a report from the American Heart Association. Circulation 137(12): e67e492. 10.1161/CIR.0000000000000558 [PubMed: 29386200]

2. Russo CA, Elixhauser A (2006) Hospitalizations in the elderly population, 2003: statistical Brief \#6. In: Healthcare Cost and Utilization Project (HCUP) Statistical Briefs Rockville

3. Nkomo VT, Gardin JM, Skelton TN, Gottdiener JS, Scott CG, Enriquez-Sarano M (2006) Burden of valvular heart diseases: a population-based study. Lancet 368(9540):1005-1011. 10.1016/ S0140-6736(06)69208-8 [PubMed: 16980116]

4. Heidenreich PA, Albert NM, Allen LA, Bluemke DA, Butler J, Fonarow GC, Ikonomidis JS, Khavjou O, Konstam MA, Maddox TM, Nichol G, Pham M, Pina IL, Trogdon JG, American Heart Association Advocacy Coordinating C, Council on Arteriosclerosis T, Vascular B, Council on Cardiovascular R, Intervention, Council on Clinical C, Council on E, Prevention, Stroke C (2013) Forecasting the impact of heart failure in the United States: a policy statement from the American Heart Association. Circ Heart Fail 6(3):606-619. 10.1161/HHF.0b013e318291329a [PubMed: 23616602]

5. Gupta D, Georgiopoulou VV, Kalogeropoulos AP, Dunbar SB, Reilly CM, Sands JM, Fonarow GC, Jessup M, Gheorghiade M, Yancy C, Butler J (2012) Dietary sodium intake in heart failure. Circulation 126(4):479-485. 10.1161/CIRCULATIONAHA.111.062430 [PubMed: 22825409]

6. Konerman MC, Hummel SL (2014) Sodium restriction in heart failure: benefit or harm? Curr Treat Options Cardiovasc Med 16(2):286 10.1007/s11936-013-0286-x [PubMed: 24398803]

7. Ponikowski P, Voors AA, Anker SD, Bueno H, Cleland JGF, Coats AJS, Falk V, Gonzalez-Juanatey JR, Harjola VP, Jankowska EA, Jessup M, Linde C, Nihoyannopoulos P, Parissis JT, Pieske B, Riley JP, Rosano GMC, Ruilope LM, Ruschitzka F, Rutten FH, van der Meer P, Group ESCSD (2016) 2016 ESC Guidelines for the diagnosis and treatment of acute and chronic heart failure: the task 
force for the diagnosis and treatment of acute and chronic heart failure of the European Society of Cardiology (ESC) developed with the special contribution of the Heart Failure Association (HFA) of the ESC. Eur Heart J 37(27):2129-2200. 10.1093/eurheartj/ehw128 [PubMed: 27206819]

8. Mimran A, Guiod L, Hollenberg NK (1974) The role of angiotensin in the cardiovascular and renal response to salt restriction. Kidney Int 5(5):348-355 [PubMed: 4372449]

9. Masson S, Solomon S, Angelici L, Latini R, Anand IS, Prescott M, Maggioni AP, Tognoni G, Cohn JN, Val-Heft I (2010) Elevated plasma renin activity predicts adverse outcome in chronic heart failure, independently of pharmacologic therapy: data from the Valsartan Heart Failure Trial (ValHeFT). J Card Fail 16(12):964-970. 10.1016/j.cardfail.2010.06.417 [PubMed: 21111986]

10. Aliti GB, Rabelo ER, Clausell N, Rohde LE, Biolo A, Beck-da-Silva L (2013) Aggressive fluid and sodium restriction in acute decompensated heart failure: a randomized clinical trial. JAMA Intern Med 173(12):1058-1064. 10.1001/jamainternmed.2013.552 [PubMed: 23689381]

11. Damgaard M, Norsk P, Gustafsson F, Kanters JK, Christensen NJ, Bie P, Friberg L, Gadsboll N (2006) Hemodynamic and neuroendocrine responses to changes in sodium intake in compensated heart failure. Am J Phys Regul Integr Comp Phys 290(5):R1294-R1301. 10.1152/ajpregu. 00738.2005

12. Paterna S, Parrinello G, Cannizzaro S, Fasullo S, Torres D, Sarullo FM, Di Pasquale P (2009) Medium term effects of different dosage of diuretic, sodium, and fluid administration on neurohormonal and clinical outcome in patients with recently compensated heart failure. Am J Cardiol 103(1):93-102. 10.1016/j.amjcard.2008.08.043 [PubMed: 19101237]

13. Paterna S, Fasullo S, Parrinello G, Cannizzaro S, Basile I, Vitrano G, Terrazzino G, Maringhini G, Ganci F, Scalzo S, Sarullo FM, Cice G, Di Pasquale P (2011) Short-term effects of hypertonic saline solution in acute heart failure and long-term effects of a moderate sodium restriction in patients with compensated heart failure with New York Heart Association class III (Class C) (SMAC-HF Study). Am J Med Sci 342(1):27-37. 10.1097/MAJ.0b013e31820f10ad [PubMed: 21701268]

14. Mahtani KR, Heneghan C, Onakpoya I, Tierney S, Aronson JK, Roberts N, Hobbs FDR, Nunan D (2018) Reduced salt intake for heart failure: a systematic review. JAMA Intern Med 178(12): 1693-1700. 10.1001/jamainternmed.2018.4673 [PubMed: 30398532]

15. Arcand J, Floras JS, Azevedo E, Mak S, Newton GE, Allard JP (2011) Evaluation of 2 methods for sodium intake assessment in cardiac patients with and without heart failure: the confounding effect of loop diuretics. Am J Clin Nutr 93(3):535-541. 10.3945/ajcn.110.004457 [PubMed: 21191141]

16. Arcand J, Ivanov J, Sasson A, Floras V, Al-Hesayen A, Azevedo ER, Mak S, Allard JP, Newton GE (2011) A high-sodium diet is associated with acute decompensated heart failure in ambulatory heart failure patients: a prospective follow-up study. Am J Clin Nutr 93(2):332-337. 10.3945/ajcn. 110.000174 [PubMed: 21084647]

17. Spaderna H, Zahn D, Pretsch J, Connor SL, Zittermann A, Schulze Schleithoff S, Bramstedt KA, Smits JM, Weidner G (2013) Dietary habits are related to outcomes in patients with advanced heart failure awaiting heart transplantation. J Card Fail 19(4):240-250. 10.1016/j.cardfail.2013.02.004 [PubMed: 23582090]

18. Lennie TA, Song EK, Wu JR, Chung ML, Dunbar SB, Pressler SJ, Moser DK (2011) Three gram sodium intake is associated with longer event-free survival only in patients with advanced heart failure. J Card Fail 17(4):325-330. 10.1016/j.cardfail.2010.11.008 [PubMed: 21440871]

19. Williams B, Mancia G, Spiering W, Agabiti Rosei E, Azizi M, Burnier M, Clement DL, Coca A, de Simone G, Dominiczak A, Kahan T, Mahfoud F, Redon J, Ruilope L, Zanchetti A, Kerins M, Kjeldsen SE, Kreutz R, Laurent S, Lip GYH, McManus R, Narkiewicz K, Ruschitzka F, Schmieder RE, Shlyakhto E, Tsioufis C, Aboyans V, Desormais I, Group ESCSD (2018) 2018 ESC/ESH Guidelines for the management of arterial hypertension. Eur Heart J 39(33):3021-3104. 10.1093/eurheartj/ehy339 [PubMed: 30165516]

20. Rahman A, Jafry S, Jeejeebhoy K, Nagpal AD, Pisani B, Agarwala R (2016) Malnutrition and cachexia in heart failure. JPEN J Parenter Enteral Nutr 40(4):475-486. 10.1177/0148607114566854 [PubMed: 25634161]

21. Levitan EB, Wolk A, Mittleman MA (2009) Consistency with the DASH diet and incidence of heart failure. Arch Intern Med 169(9): 851-857. 10.1001/archinternmed.2009.56 [PubMed: 19433696] 
22. Jefferson K, Ahmed M, Choleva M, Mak S, Allard JP, Newton GE, Arcand J (2015) Effect of a sodium-restricted diet on intake of other nutrients in heart failure: implications for research and clinical practice. J Card Fail 21(12):959-962. 10.1016/j.cardfail.2015.10.002 [PubMed: 26497756]

23. Poehlman ET, Scheffers J, Gottlieb SS, Fisher ML, Vaitekevicius P (1994) Increased resting metabolic rate in patients with congestive heart failure. Ann Intern Med 121(11):860-862 [PubMed: 7772113]

24. Dunn SP, Bleske B, Dorsch M, Macaulay T, Van Tassell B, Vardeny O (2009) Nutrition and heart failure: impact of drug therapies and management strategies. Nutr Clin Pract 24(1):60-75. 10.1177/0884533608329299 [PubMed: 19244150]

25. Anker SD, Sharma R (2002) The syndrome of cardiac cachexia. Int J Cardiol 85(1):51-66 [PubMed: 12163209]

26. Kalantar-Zadeh K, Anker SD, Horwich TB, Fonarow GC (2008) Nutritional and anti-inflammatory interventions in chronic heart failure. Am J Cardiol 101(11A):89E-103E. 10.1016/j.amjcard. 2008.03.007

27. Jimenez Jimenez FJ, Cervera Montes M, Blesa Malpica AL, Metabolism, Nutrition Working Group of the Spanish Society of Intensive Care M, Coronary u (2011) Guidelines for specialized nutritional and metabolic support in the critically-ill patient: update. Consensus SEMICYUCSENPE: cardiac patient. Nutr Hosp 26(Suppl 2):76-80. 10.1590/S0212-16112011000800017 [PubMed: 22411526]

28. Ceconi C, Curello S, Bachetti T, Corti A, Ferrari R (1998) Tumor necrosis factor in congestive heart failure: a mechanism of disease for the new millennium? Prog Cardiovasc Dis 41(1 Suppl 1): 25-30 [PubMed: 9715820]

29. Anker SD, Ponikowski P, Varney S, Chua TP, Clark AL, Webb-Peploe KM, Harrington D, Kox WJ, Poole-Wilson PA, Coats AJ (1997) Wasting as independent risk factor for mortality in chronic heart failure. Lancet 349(9058):1050-1053. 10.1016/S0140-6736(96)07015-8 [PubMed: 9107242]

30. Kistorp C, Faber J, Galatius S, Gustafsson F, Frystyk J, Flyvbjerg A, Hildebrandt P (2005) Plasma adiponectin, body mass index, and mortality in patients with chronic heart failure. Circulation 112(12): 1756-1762. 10.1161/CIRCULATIONAHA.104.530972 [PubMed: 16157772]

31. Szabo T, Scherbakov N, Sandek A, Kung T, von Haehling S, Lainscak M, Jankowska EA, Rudovich N, Anker SD, Frystyk J, Flyvbjerg A, Pfeiffer AF, Doehner W (2014) Plasma adiponectin in heart failure with and without cachexia: catabolic signal linking catabolism, symptomatic status, and prognosis. Nutr Metab Cardiovasc Dis 24(1):50-56. 10.1016/j.numecd. 2013.04.015 [PubMed: 23791298]

32. Narumi T, Arimoto T, Funayama A, Kadowaki S, Otaki Y, Nishiyama S, Takahashi H, Shishido T, Miyashita T, Miyamoto T, Watanabe T, Kubota I (2013) Prognostic importance of objective nutritional indexes in patients with chronic heart failure. J Cardiol 62(5):307-313. 10.1016/j.jjcc. 2013.05.007 [PubMed: 23806549]

33. Shirakabe A, Hata N, Kobayashi N, Okazaki H, Matsushita M, Shibata Y, Nishigoori S, Uchiyama S, Asai K, Shimizu W (2018) The prognostic impact of malnutrition in patients with severely decompensated acute heart failure, as assessed using the Prognostic Nutritional Index (PNI) and Controlling Nutritional Status (CONUT) score. Heart Vessel 33(2):134-144. 10.1007/ s00380-017-1034-z

34. Sze S, Zhang J, Pellicori P, Morgan D, Hoye A, Clark AL (2017) Prognostic value of simple frailty and malnutrition screening tools in patients with acute heart failure due to left ventricular systolic dysfunction. Clin Res Cardiol 106(7):533-541. 10.1007/s00392-017-1082-5 [PubMed: 28204965]

35. Lourenco BH, Vieira LP, Macedo A, Nakasato M, Marucci Mde F, Bocchi EA (2009) Nutritional status and adequacy of energy and nutrient intakes among heart failure patients. Arq Bras Cardiol 93(5):541-548

36. Sargento L, Longo S, Lousada N, dos Reis RP (2014) The importance of assessing nutritional status in elderly patients with heart failure. Curr Heart Fail Rep 11(2):220-226. 10.1007/ s11897-014-0189-5 [PubMed: 24477904]

37. Tevik K, Thurmer H, Husby MI, de Soysa AK, Helvik AS (2015) Nutritional risk screening in hospitalized patients with heart failure. Clin Nutr 34(2):257-264. 10.1016/j.clnu.2014.03.014 [PubMed: 24755236] 
38. Gastelurrutia P, Lupon J, Domingo M, Ribas N, Noguero M, Martinez C, Cortes M, Bayes-Genis A (2011) Usefulness of body mass index to characterize nutritional status in patients with heart failure. Am J Cardiol 108(8):1166-1170. 10.1016/j.amjcard.2011.06.020 [PubMed: 21798500]

39. Casas-Vara A, Santolaria F, Fernandez-Bereciartua A, Gonzalez-Reimers E, Garcia-Ochoa A, Martinez-Riera A (2012) The obesity paradox in elderly patients with heart failure: analysis of nutritional status. Nutrition 28(6):616-622. 10.1016/j.nut.2011.10.006 [PubMed: 22261572]

40. Lennie TA, Andreae C, Rayens MK, Song EK, Dunbar SB, Pressler SJ, Heo S, Kim J, Moser DK (2018) Micronutrient deficiency independently predicts time to event in patients with heart failure. J Am Heart Assoc 7(17):e007251 10.1161/JAHA.117.007251 [PubMed: 30371170]

41. Sciatti E, Lombardi C, Ravera A, Vizzardi E, Bonadei I, Carubelli V, Gorga E, Metra M (2016) Nutritional deficiency in patients with heart failure. Nutrients 8(7). 10.3390/nu8070442

42. Arcand J, Floras V, Ahmed M, Al-Hesayen A, Ivanov J, Allard JP, Newton GE (2009) Nutritional inadequacies in patients with stable heart failure. J Am Diet Assoc 109(11):1909-1913. 10.1016/ j.jada.2009.08.011 [PubMed: 19857633]

43. McKeag NA, McKinley MC, Harbinson MT, McGinty A, Neville CE, Woodside JV, McKeown PP (2017) Dietary micronutrient intake and micronutrient status in patients with chronic stable heart failure: an observational study. J Cardiovasc Nurs 32(2):148-155. 10.1097/JCN. 0000000000000322 [PubMed: 26829748]

44. d'Almeida KS, Rabelo-Silva ER, Souza GC, Trojahn MM, Barilli SL, Mansson JV, Biolo A, Rohde LE, Clausell N, Beck-da-Silva L (2014) Effect of fluid and dietary sodium restriction in the management of patients with heart failure and preserved ejection fraction: study protocol for a randomized controlled trial. Trials 15:347 10.1186/1745-6215-15-347 [PubMed: 25187436]

45. Jacobsson A, Pihl-Lindgren E, Fridlund B (2001) Malnutrition in patients suffering from chronic heart failure; the nurse's care. Eur J Heart Fail 3(4):449-456 [PubMed: 11511431]

46. Akashi YJ, Springer J, Anker SD (2005) Cachexia in chronic heart failure: prognostic implications and novel therapeutic approaches. Curr Heart Fail Rep 2(4):198-203 [PubMed: 16332313]

47. Rifai L, Silver MA (2016) A review of the DASH diet as an optimal dietary plan for symptomatic heart failure. Prog Cardiovasc Dis 58(5):548-554. 10.1016/j.pcad.2015.11.001 [PubMed: 26545444]

48. Williams B, Mancia G, Spiering W, Agabiti Rosei E, Azizi M, Burnier M, Clement D, Coca A, De Simone G, Dominiczak A, Kahan T, Mahfoud F, Redon J, Ruilope L, Zanchetti A, Kerins M, Kjeldsen S, Kreutz R, Laurent S, Lip GYH, McManus R, Narkiewicz K, Ruschitzka F, Schmieder R, Shlyakhto E, Tsioufis K, Aboyans V, Desormais I (2018) 2018 Practice Guidelines for the management of arterial hypertension of the European Society of Hypertension (ESH) and the European Society of Cardiology (ESC). Blood Press 27(6):314-340. 10.1080/08037051.2018.1527177 [PubMed: 30380928]

49. Williams B, Mancia G, Spiering W, Agabiti Rosei E, Azizi M, Burnier M, Clement D, Coca A, De Simone G, Dominiczak A, Kahan T, Mahfoud F, Redon J, Ruilope L, Zanchetti A, Kerins M, Kjeldsen S, Kreutz R, Laurent S, Lip GYH, McManus R, Narkiewicz K, Ruschitzka F, Schmieder R, Shlyakhto E, Tsioufis K, Aboyans V, Desormais I, List of authors/Task Force m (2018) 2018 Practice Guidelines for the management of arterial hypertension of the European Society of Hypertension and the European Society of Cardiology: ESH/ESC task force for the management of arterial hypertension. J Hypertens 36(12):2284-2309. 10.1097/HJH.0000000000001961 [PubMed: 30379783]

50. Cohen JB, Townsend RR (2018) The ACC/AHA 2017 hypertension guidelines: both too much and not enough of a good thing? Ann Intern Med 168(4):287-288. 10.7326/M17-3103 [PubMed: 29204627]

51. Greenland P, Peterson E (2017) The new 2017 ACC/AHA guidelines "up the pressure" on diagnosis and treatment of hypertension. JAMA 318(21):2083-2084. 10.1001/jama.2017.18605 [PubMed: 29159417]

52. Lloyd-Jones DM, Larson MG, Leip EP, Beiser A, D’Agostino RB, Kannel WB, Murabito JM, Vasan RS, Benjamin EJ, Levy D, Framingham Heart S (2002) Lifetime risk for developing congestive heart failure: the Framingham Heart Study. Circulation 106(24):3068-3072 [PubMed: 12473553] 
53. Sanches Machado d'Almeida K, Ronchi Spillere S, Zuchinali P, Correa Souza G (2018) Mediterranean diet and other dietary patterns in primary prevention of heart failure and changes in cardiac function markers: a systematic review. Nutrients 10(1). 10.3390/nu10010058

54. Rifai L, Pisano C, Hayden J, Sulo S, Silver MA (2015) Impact of the DASH diet on endothelial function, exercise capacity, and quality of life in patients with heart failure. Proc (Bayl Univ Med Cent) 28(2):151-156 [PubMed: 25829641]

55. Levitan EB, Lewis CE, Tinker LF, Eaton CB, Ahmed A, Manson JE, Snetselaar LG, Martin LW, Trevisan M, Howard BV, Shikany JM (2013) Mediterranean and DASH diet scores and mortality in women with heart failure: the Women's Health Initiative. Circ Heart Fail 6(6):1116-1123. 10.1161/CIRCHEARTFAILURE.113.000495 [PubMed: 24107587]

56. Hummel SL, Seymour EM, Brook RD, Kolias TJ, Sheth SS, Rosenblum HR, Wells JM, Weder AB (2012) Low-sodium dietary approaches to stop hypertension diet reduces blood pressure, arterial stiffness, and oxidative stress in hypertensive heart failure with preserved ejection fraction. Hypertension 60(5):1200-1206. 10.1161/HYPERTENSIONAHA.112.202705 [PubMed: 23033371]

57. Hummel SL, Seymour EM, Brook RD, Sheth SS, Ghosh E, Zhu S, Weder AB, Kovacs SJ, Kolias TJ (2013) Low-sodium DASH diet improves diastolic function and ventricular-arterial coupling in hypertensive heart failure with preserved ejection fraction. Circ Heart Fail 6(6):1165-1171. 10.1161/CIRCHEARTFAILURE.113.000481 [PubMed: 23985432]

58. Hummel SL, Karmally W, Gillespie BW, Helmke S, Teruya S, Wells J, Trumble E, Jimenez O, Marolt C, Wessler JD, Cornellier ML, Maurer MS (2018) Home-delivered meals postdischarge from heart failure hospitalization. Circ Heart Fail 11(8):e004886 10.1161/CIRCHEARTFAILURE. 117.004886 [PubMed: 30354562] 


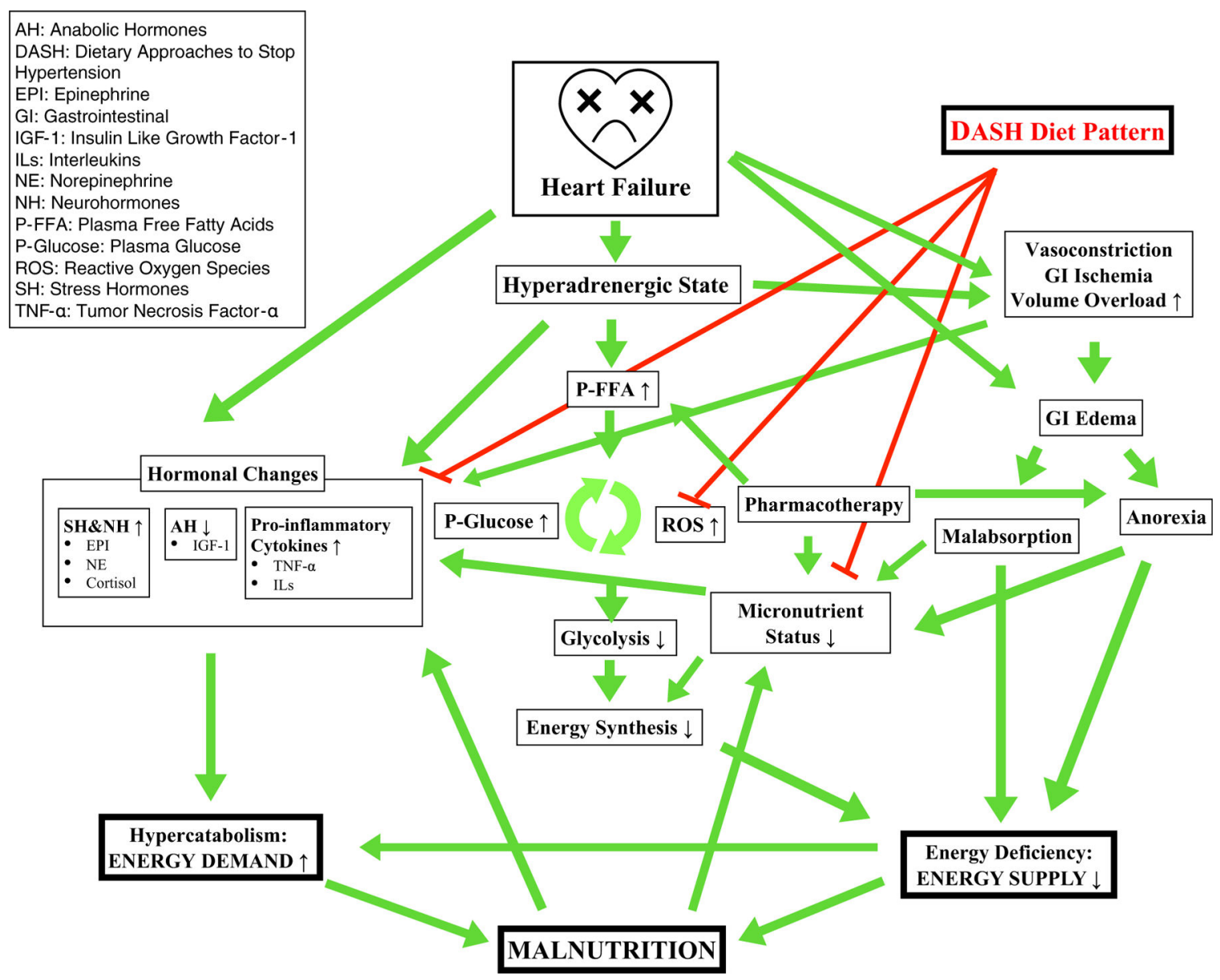

Fig. 1.

Suggested influence of the Dietary Approaches to Stop Hypertension (DASH) Diet on heart failure pathophysiology and nutritional status: a conceptual framework 


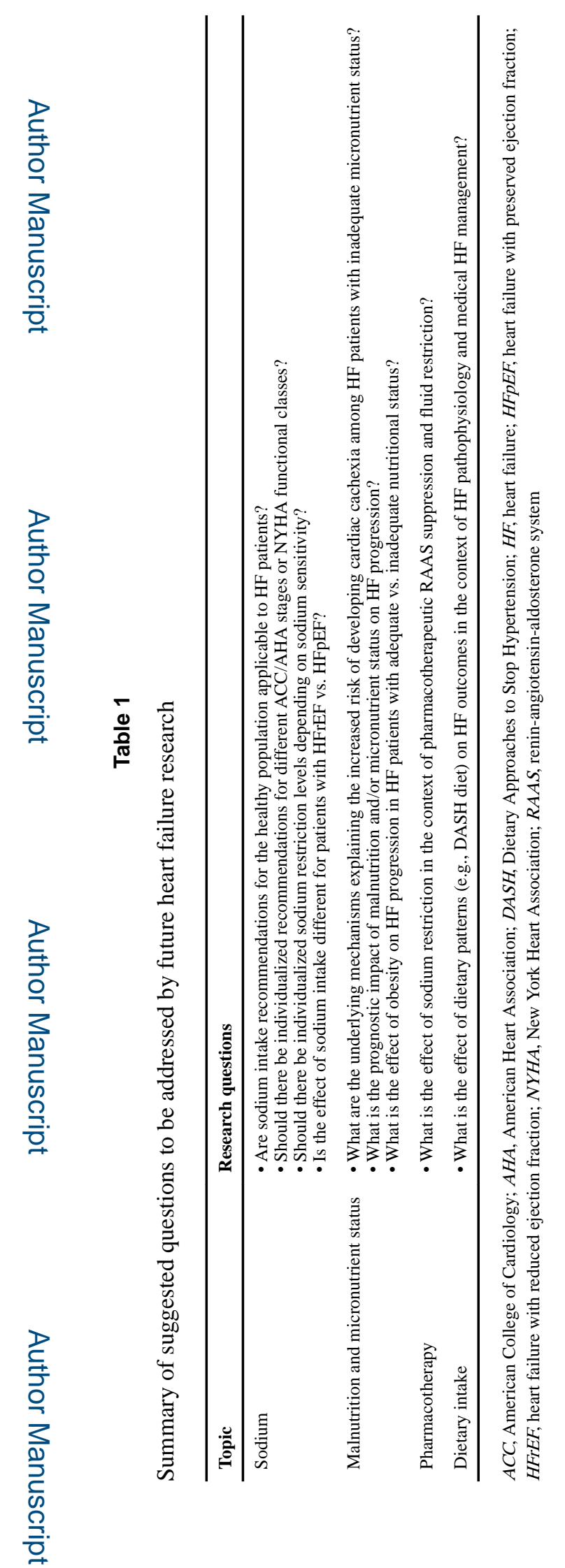

Heart Fail Rev. Author manuscript; available in PMC 2020 July 01. 